\title{
Nutritional assessment of exclusively breastfed and non-exclusively breastfed Infants aged ( $0-6$ months) at Mother of Christ Specialist Hospital, Enugu, Nigeria
}

\author{
Ndiokwelu Chika ${ }^{1}$, Nwosu Odinakachukwu ${ }^{1}$, Uwaoma Eucharia ${ }^{1}$, Maduforo Aloysius ${ }^{2}$ \\ ${ }^{1}$ Department of Nutrition and Dietetics, University of Nigeria Teaching Hospital Ituku Ozalla, Enugu State, Nigeria \\ ${ }^{2}$ Department of Dietetics, School of Biomedical and Allied Health Sciences, College of Health Sciences, University of Ghana, Legon, \\ Ghana
}

Email address:

cndiokwelu@yahoo.com (N. Chika)

\section{To cite this article:}

Ndiokwelu Chika, Nwosu Odinakachukwu, Uwaoma Eucharia, Maduforo Aloysius. Nutritional Assessment of Exclusively Breastfed and Non-Exclusively Breastfed Infants Aged (0 - 6 Months) at Mother of Christ Specialist Hospital, Enugu, Nigeria. International Journal of Nutrition and Food Sciences. Vol. 3, No. 5, 2014, pp. 462-470. doi: 10.11648/j.ijnfs.20140305.25

\begin{abstract}
Background: The assessment of Nutritional status of infants, aged 0-6 Months (Exclusively breastfed and nonexclusively breastfed) was conducted at Mother of Christ Specialist Hospital, Ogui, Enugu State, Nigeria. The aim of the survey was to find out if mothers truly practice exclusive breastfeeding, the ratio of mothers who practice exclusive breastfeeding to those who do not, to compare the nutritional status of infants who were breastfed exclusively with those who were not and to find out factors that discouraged mothers from practicing exclusive breastfeeding. Methodology: Structured questionnaires were validated by Dietitians and administered. The questionnaires were administered to two hundred mothers who were randomly selected. Anthropometric measurements (weight, length, head circumference and chest circumference) of babies were taken and recorded. The data collected were analyzed using statistical methods, which included mean, chi square, t-test, z-score, correlations, frequencies and percentages. Result: The study, revealed that (194) mothers breastfed their babies generally while (6) did not. One hundred and Sixty four (82\%) practiced exclusive breastfeeding and 15\% (30) did not breastfeed their babies exclusively. There was significant relationship between the levels of mothers' education and nutritional status of the infants. The mean age of the males exclusively breastfed was (9.86) while that of the females was (9.74) and the mean length was (61.96) and (60.92) receptively. The result of the anthropometric measurements showed that most of the parameters were better in exclusively breastfeed than in nonexclusively breastfeed infants though in some of the parameters, they were similar or better. The result of Z- scores for weight of male infants exclusively breastfed and non-exclusively breastfed were the same, while the length of the exclusively breastfed and non-exclusively breastfed were 30\% and $26 \%$ respectively. Wrong concept of exclusive breastfeeding and its wrong application were found to be the major factors affecting nutritional status of infants.
\end{abstract}

Keywords: Nutritional, Assessment, Infants, Exclusively, Non-Exclusively, Breastfeed

\section{Introduction}

Adequate nutrition during infancy and early childhood is fundamental to the development of each child's full human potential. It is well recognized that the period from birth to two years of age is a "critical window" for the promotion of optimal growth, health and behavioural development. Poor nutrition leads to ill-health and ill-health contributes to further deterioration in nutritional status. These effects are most dramatically observed in infants and young children. They suffer the highest risk of disability and death associated with it. In Nigeria, studies have indicated a high prevalence of malnutrition ${ }^{(1-4)}$. Both exclusive breastfeeding up to 6 months and continued breastfeeding after 6 months are crucial in reducing the risk of diarrhoea and other illnesses in older children, which is heightened in emergencies ${ }^{(5)}$.

"Breastfeeding is nearly universal in Nigeria, with 97\% of children ever breastfed. On average, children breastfeed until the age of 18 months. WHO recommends that children receive nothing but breast milk (exclusive 
breastfeeding) for the first six months of life. In Nigeria, only $17 \%$ of children under six months are exclusively breastfed $^{(5)}$ Infants should not be given water, juices, other milks, or complementary foods until six months of age, yet $87 \%$ of Nigerian infants under six months receive complementary liquids or foods. ${ }^{(6)}$

Under the influence of the hormones prolactin and oxytocin, women produce milk after childbirth to feed the baby. The initial milk produced is often referred to as colostrum, which is high in immunoglobulin A ( $\lg \mathrm{A})$ which coats the gastrointestinal track. This helps to protect the new born until it's own Immune system is functioning properly along with creating a mild laxative effect, helping in expelling meconium and preventing the build-up of bilirubin (a contributory factor in jaundice) ${ }^{(7)}$.

Optimal infant and young child feeding includes six months of exclusive breastfeeding, starting at delivery, and continued breastfeeding with appropriate complementary foods and feeding for two years and beyond, as well as related maternal nutrition and care ${ }^{(8)}$.

"As a global public health recommendation, infants should be exclusively breastfed for the first six months of life to achieve optimal growth, development and health. Thereafter, to meet their evolving nutritional needs, infants should receive safe and nutritionally adequate complementary foods while breastfeeding continues for up to two years of age or beyond."(6)

The concept of exclusive breastfeeding was jointly established by WHO/UNICEF for the sole purpose of protecting, promoting and supporting breastfeeding among women ${ }^{(9)}$. This is because breastmilk is the ideal food for the healthy growth and development of the baby. Concerned about the well being of the child and particularly about the rising rate of infant mortality, the Innocenti Declaration of (1990) clearly and unequivocally "affirmed the right of every child to adequate nutrition and care". There is no doubt that nutrition plays a major role in the general health status of the individual. Therefore, in order to ensure proper and adequate nutrition for the baby, it is necessary to give the baby that food which is naturally endowed with all the nutritional requirements needed for the first six months of life and that is breastmilk ${ }^{(9)}$.

The challenge of hunger which hampers the nutritional status of children and women still remains an issue of concern in Nigeria. Child malnutrition remains a major public health challenge in the developing world. Globally, about 6.6 million children under 5 years of age died in 2012, mostly from preventable causes ${ }^{(10)}$. It has been established that more than $54 \%$ of under -5 deaths in developing countries is associated with malnutrition. Nigeria Demographic and Health Survey (NDHS) revealed that under-5 mortality rate decreased from 201 deaths per 1,000 live births in 2003 to 128 deaths per 1,000 live births in the 2013 NDHS $^{(11-12)}$. However, Nigeria still has a long way to go to achieve the millennium development goals (MDGs) target of reducing the under-5 mortality to 64 deaths per 1,000 live births and the infant mortality to 30 deaths per 1,000 live births by $2015^{(13)}$. The estimated infant mortality rate in the 2003 NDHS was 100 deaths per 1,000 live births, which decreased to 75 deaths per 1,000 live births in the 2008 NDHS and further to 69 deaths per 1,000 live births in the 2013 NDHS. The pattern shows that about 29 percent of deaths under age 5 occur during the neonatal period ( 37 deaths per 1,000 live births), and 24 percent occur during the post-neonatal period (31 deaths per 1,000 live births) ${ }^{(12)}$.

The poor indices of nutritional status of Nigerian children makes it imperative to assess the level of exclusive breastfeeding within the subject area. It is hoped that the results of this study which is rather scarce in Enugu especially in the study facility will help the relevant authorities in re-invigorating baby friendly activities in the State especially at Mother of Christ Specialist hospital which is a faith-based health facility and heavily patronized by pregnant women..

The general objective of the study was to determine the nutritional status of exclusively and non- exclusively breastfed infants aged $0-6$ months at Mother of Christ Specialist Hospital, Enugu.

The specific objectives were to:

1. Determine if the mothers at the Baby Friendly health facility truly practice exclusive breastfeeding.

2. Determine the ratio of mothers who practice exclusive breastfeeding to those who do not.

3. Compare the nutritional status of infants who were breastfeed exclusively with those who were not.

4. Document some of the factors that discourage mothers from practicing exclusive breastfeeding.

\section{Materials and Method}

\subsection{Study Location}

The study was conducted at Mother of Christ Specialist Hospital Ogui, Enugu.

\subsection{Sample Size}

Two hundred women and their babies were used for this study.

\subsection{Questionnaire}

The questions were divided into parts with 50 questions in all. The parts are A-E which included infants' characteristics, parents' personal data, exclusive breastfeeding and nutrition knowledge questions. The data were collected with the aid of questionnaires given to mothers to complete or administered through oral interview. This detailed questionnaire was designed to obtain information on the nutritional status of infants aged $(0-6)$ months who were exclusively breastfed or non-exclusively breastfed at Mother of Christ Specialist Hospital Ogui, Enugu State. 


\subsection{Materials}

The materials used for this study included: a measuring tape (Shanghai, China) of 60 inches $(150 \mathrm{~cm})$ in length; a paediatric beam balance scale (salter model 180 made in England) of capacity $(15 \mathrm{~kg} \times 50 \mathrm{~g})$

\subsection{Procedure}

The weighing balance was placed on a table of $70 \mathrm{~cm}$ height and zeroed. The infants were placed on the scale and their weights were read and recorded. The scale was recalibrated with a known weight after ten weighing. The birth weight of the infants were obtained from their respective growth monitoring chart.

\subsection{Length}

While the baby was lying on a flat surface, the lengths of the babies were obtained with a measuring tape and recoded.

\subsection{Chest Circumference}

The tape was placed at burst level while the subject was breathing normally; the measurement was taken under the armpit over the shoulder blades and across the nipple.

\subsection{Method of Data Analysis}

T-test, chi square test, Z-scores, correlation, frequencies and percentages were used for analyzing the data.

\section{Result}

Table 1. Age of Babies.

\begin{tabular}{lll}
\hline Age & Frequency & Percentage (\%) \\
\hline $0-11$ weeks & 130 & 65 \\
$12-24$ weeks & 70 & 35 \\
Total & 200 & 100 \\
\hline
\end{tabular}

Table 1 presents the age of the babies (0-6months). Sixty five percent- $65 \%$ (130) were between $0-11$ weeks while $35 \%$ (70) were between $12-24$ weeks.

Table 2. Method of Birth.

\begin{tabular}{lll}
\hline & Frequency & Percentage (\%) \\
\hline Vertex & 166 & 83 \\
Caesarean & 34 & 17 \\
Total & 200 & 100 \\
\hline
\end{tabular}

From table 2, it could be seen that $83 \%$ of the subjects were delivered by means of spontaneous vertex delivery while $17 \%$ (34) were by caesarean section.

Table 3. Birth Weight

\begin{tabular}{lll}
\hline Weight & Frequency & Percentage (\%) \\
\hline $0-3.5 \mathrm{~kg}$ & 128 & 64 \\
3.6 and above & 72 & 36 \\
Total & 200 & 100 \\
\hline
\end{tabular}

From table 3 ; it is shown that majority $(64 \%)$ of the subjects had birth weights between $0-3.5 \mathrm{~kg}$, while $36 \%$, were $3.6 \mathrm{~kg}$ and above.

Table 4. Age Distribution of Respondents $(n=200)$.

\begin{tabular}{lll}
\hline Age & Frequency & Percentage (\%) \\
\hline$<20$ years & 4 & 2 \\
$21-25$ & 50 & 25 \\
$26-30$ & 80 & 40 \\
$31-35$ & 40 & 20 \\
$36-40$ & 16 & 8 \\
$41-45$ & 4 & 2 \\
45 and above & - & - \\
No response & 6 & 3 \\
Total & 200 & 100 \\
\hline
\end{tabular}

The age of the mothers of the babies used for this study ranged from below 20 years of age to 45 years.

\subsection{Education of Respondent}

Sixty five percent $(65 \%)$ of the mothers who participated in this study attained post secondary level education, 30\% attained secondary school level education while 3\% did not attain primary school level education. Two percent $-2 \%$ (4) of the respondents did not respond.

\subsection{Occupation of Respondent and their Husband}

The occupation of husbands and their wives. 1\% (2) of both the men and women were farmers. $20 \%$ and $35 \%$ were traders likewise $32 \%$ and $36 \%$ were civil servants. Five percent (5\%) and $8 \%$ were artisans while 32 and $15 \%$ were unskilled.

Table 5. Religion of Respondents $(n=200$. $)$

\begin{tabular}{lll}
\hline religion & Number & Percentage (\%) \\
\hline African Traditional Religion & - & - \\
Islam & - & - \\
Christianity & 200 & 200 \\
Total & 200 & 100 \\
\hline
\end{tabular}

It can be seen from table 5 that all the respondents (100\%) were all Christians.

Table 6. Parity of Respondents.

\begin{tabular}{lll}
\hline Parity & Number & Percentage (\%) \\
\hline $1-3$ & 82 & 41 \\
$4-6$ & 30 & 15 \\
$7-9$ & 10 & 5 \\
10 and above & 3 & 1.5 \\
No responses & 75 & 37.5 \\
Total & 200 & 100 \\
\hline
\end{tabular}

Table 6 above, shows that $41 \%$ of the women have 1-3 children (15\%) have 4-6, (5\%) have $7-9,(1.5 \%)$ have 10 children and above while (37.5\%) did not attempt the questions. 
Table 7. Range of Monthly Income of Respondents and their Husbands.

\begin{tabular}{lllll}
\hline & Number & Percentage (\%) & Number & Percentage (\%) \\
\hline$<5,000$ & 14 & 7 & 32 & 16 \\
$6-10,000$ & 12 & 6 & 50 & 25 \\
$11-20,000$ & 28 & 14 & 25 & 12.5 \\
$21-30,000$ & 18 & 9 & 34 & 17 \\
$31-40,000$ & 20 & 10 & 4 & 2 \\
$41-50,000$ & 6 & 3 & 4 & 2 \\
51 and & 36 & 18 & 29 & 11 \\
above & & 33 & 29 & 14.5 \\
No response & 66 & 100 & 200 & 100 \\
Total & 200 & & & \\
\hline
\end{tabular}

Table 7 presents the monthly income of the women and their husbands, which ranges from less than N5, 000 to above N51, $000.18 \%$ of the men and $11 \%$ of the women earn above N51,000.00 respectively, like wise $7 \%$ of the men and $16 \%$ of the women earn less than N5,00.00 respectively while $6 \%$ and $25 \%$ earn between N6 - 10,000. Also, $3 \%$ of the men and $2 \%$ of the women earn between $\mathrm{N} 41-50,000$ while the rest earn between N11, $000-$ 40,$000 ; 14.5 \%$ of the women and $33 \%$ of the men's income were not disclosed.

Table 8. Residential Locations.

\begin{tabular}{lll}
\hline Location & Number & Percentage (\%) \\
\hline Urban & 120 & 60 \\
Semi Urban & 26 & 13 \\
Rural & 26 & 13 \\
No response & 28 & 14 \\
Total & 200 & 100 \\
\hline
\end{tabular}

Table 8 shows that, a greater number of the respondents $(60 \%)$ live in the urban area, (13\%) lived both in semi urban and rural area, while (14\%) gave no answer.

\subsection{Breastfeeding}

Table 9. Time of Initiation of Breastfeeding.

\begin{tabular}{lll}
\hline Period & Number & Percentage (\%) \\
\hline Within $24 \mathrm{~h}$ & 146 & 73 \\
Within 48h & 12 & 6 \\
Within 72h & 16 & 8 \\
72h and above & 12 & 6 \\
No response & 14 & 7 \\
Total & 200 & 100 \\
\hline
\end{tabular}

Majority of the women used for this study breastfed their babies. From the table above, it is seen that $73 \%$ (146) of the mothers breastfed their babies the same day they delivered.

Table 10. Duration of Exclusive Breastfeeding.

\begin{tabular}{lll}
\hline duration & Number & Percentage (\%) \\
\hline $1-2$ months & 26 & 13 \\
$3-4$ months & 50 & 25 \\
$5-6$ months & 88 & 44 \\
Others & - & - \\
No response & 36 & 18 \\
Total & 200 & 100 \\
\hline
\end{tabular}

Table 10 summarizes the length of time mothers practiced exclusive breastfeeding. Thirteen percent (13\%) of the respondents practiced exclusively breastfeeding for 1-2 months while (44\%) practiced between 5-6 months. The remaining (18\%) did not respond.

Table 11. Frequency of Breastfeeding.

\begin{tabular}{lll}
\hline Frequency & Number & Percentage (\%) \\
\hline On demand & 126 & 63 \\
$<3$ times & 4 & 2 \\
$4-7$ times & 4 & 2 \\
$8-11$ times & 4 & 7 \\
Above 12 times & 14 & 22 \\
No response & 44 & 4 \\
Total & 200 & 100 \\
\hline
\end{tabular}

From the table above, it is shown that majority of the mothers $(63 \%)$ breastfed above 12 times, $(7 \%)$ breastfed between 8 to 11 times while $(2 \%)$ breastfed less than 3 times a well as 4-7 times.

Table 12. Frequency of Giving Water.

\begin{tabular}{lll}
\hline Frequency of giving water & Number & $\begin{array}{l}\text { Percentage } \\
(\%)\end{array}$ \\
\hline Once daily & 2 & 1 \\
2 times daily & 10 & 5 \\
3 times daily & 10 & 5 \\
Regularly & 16 & 8 \\
No water & 29 & 10 \\
No response & 122 & 61 \\
Total & 200 & 100 \\
\hline
\end{tabular}

The number of times babies given water varied from mother to mother. Table 12 shows that $1 \%$ (2) of the mothers gave water once daily to their babies. Five percent (5\%) gave 2 to 3 times daily while $8 \%$ gave water regularly. However $10 \%$ did not give water at all whereas $61 \%$ (122) did not respond to the question.

Table 13. Feeling Satisfied after being Breastfed.

\begin{tabular}{lll}
\hline Felt satisfied after breastfeeding & Number & Percentage (\%) \\
\hline Yes & 150 & 75 \\
No & 14 & 7 \\
No response & 36 & 18 \\
Total & 200 & 100 \\
\hline
\end{tabular}

The level of the babies' satiety revealed that breast milk satisfied $75 \%$ (150) of the babies, and did not satisfy $7 \%$ of the babies.However, $18 \%$ did not respond to the question.

\section{Commercial Formula}

Table 14. The Instruction on Commercial Formula.

\begin{tabular}{lll}
\hline Giving Baby Formula & Number & $\begin{array}{l}\text { Percentage } \\
\mathbf{( \% )}\end{array}$ \\
\hline Yes & 30 & 15 \\
No & 164 & 82 \\
No response & 6 & 3 \\
Total & 200 & 100 \\
\hline
\end{tabular}


As to whether mothers give formula, $(15 \%)$ responded yes to the question. (82\%) responded no, while $(3 \%)$ did not respond to the question at all.

Table 15. Reasons for Giving Formula

\begin{tabular}{lll}
\hline reasons & Number & $\begin{array}{l}\text { Percentage } \\
(\mathbf{\%})\end{array}$ \\
\hline Better and modern way of feeding & - & - \\
Contains more nutrients & - & - \\
Mother started work & 10 & 5 \\
Saves time and pain & - & - \\
Breast milk not enough & 20 & 10 \\
No response & 170 & 85 \\
Total & 200 & 100 \\
\hline
\end{tabular}

Table 15 outlines some of the reasons why some of the mothers gave formula to babies. Five percent $(5 \%)$ reported that it was due to their work, $10 \%$ said that breast milk was not enough while $85 \%$ (170) did not respond.

Table 16. Reasons for Not Giving Formula.

\begin{tabular}{lll}
\hline Reasons & Number & $\begin{array}{l}\text { Percentage } \\
(\%)\end{array}$ \\
\hline Difficult to prepare & - & - \\
Expensive & 12 & 6 \\
Does not satisfy baby & 4 & 2 \\
Gives diarrhea and vomiting & - & - \\
Others & - & - \\
No response & 184 & 92 \\
Total & 200 & 100 \\
\hline
\end{tabular}

Table 16 summarizes the reasons for not giving formula to babies. $(60 \%)$ reported that it is expensive $(2 \%)$ indicated that it does not satisfy baby while (92\%) did not respond to the question.

Table 17. Age of Introduction of Infant Formula.

\begin{tabular}{lll}
\hline \multicolumn{1}{l}{ Age } & Number & Percentage (\%) \\
\hline $\begin{array}{l}\text { Immediately after } \\
\text { birth }\end{array}$ & - & - \\
Few days after birth & 8 & 4 \\
Others & 164 & 82 \\
No response & 28 & 14 \\
Total & 200 & 100 \\
\hline
\end{tabular}

As show in table 17, (4\%) of the mothers gave formula to their babies few days after birth while (82\%) did otherwise.

Table 18. Source of Water used in Preparing Formula.

\begin{tabular}{lll}
\hline Source & Number & $\begin{array}{l}\text { Percentage } \\
(\%)\end{array}$ \\
\hline Rain water & 2 & 1 \\
Water from stream & - & - \\
Water from tanker driver & 2 & 1 \\
Tap water & 12 & 6 \\
Others & 4 & 2 \\
No response & 180 & 90 \\
Total & 200 & 100 \\
\hline
\end{tabular}

From the table $1 \%$ of the mothers got the water used to prepare baby's formula from rain water and tanker drivers vending water from boreholes respectively, $6 \%$ got from tap water while other sources were $2 \%$. (90\%) did not respond to the question.

Table 19. Type of Water used in Preparing the Formula.

\begin{tabular}{lll}
\hline Type & Number & Percentage (\%) \\
\hline Hot water & 12 & 6 \\
Hot water mixed with cold water & 10 & 5 \\
Others & - & - \\
No response & 178 & 89 \\
Total & 200 & 100 \\
\hline
\end{tabular}

Table 19 summarizes the type of water used to prepare baby's milk. Six percent $(6 \%)$ of the mothers used hot water, $5 \%$ used hot water mixed with cold water while $89 \%$ did not respond.

Table 20. Sterilization of Feeding Utensils.

\begin{tabular}{lll}
\hline sterilized & Number & Percentage (\%) \\
\hline Yes & 24 & 12 \\
No & - & - \\
No response & 176 & 88 \\
Total & 200 & 100 \\
\hline
\end{tabular}

Table 20 that $(12 \%)$ of the mothers sterilized the baby's feeding utensils. $(88 \%)$ of the respondent did not respond to the question.

Table 21. Method of Sterilization.

\begin{tabular}{lll}
\hline Method & Number & Percentage (\%) \\
\hline & & \\
Sterilization tablet & 4 & 2 \\
Hot water & 16 & 8 \\
Milton & 6 & 3 \\
Others & - & - \\
No response & 174 & 87 \\
Total & 200 & 100 \\
\hline
\end{tabular}

Table 21 summarizes some of the things used in sterilizing babies feeding utensils. Two percent $(2 \%)$ of the mothers use sterilizing tablet, $(8 \%)$ use hot water while (3\%) use Milton hypochlorite solution while (87\%), did not respond to the question.

Table 22. Giving of Left over Infant Formula.

\begin{tabular}{lll}
\hline Gave Left Over Formula & Number & Percentage (\%) \\
\hline Yes & 6 & 3 \\
No & 20 & 10 \\
No response & 174 & 87 \\
Total & 200 & 100 \\
\hline
\end{tabular}

Table 22 shows that (3\%) of the mother-s gave left over infant formula to their babies while (10\%) did not. (87\%) did not respond to the question. 
Table 23. Method of Storage of Left over Formula.

\begin{tabular}{lll}
\hline Method & Number & Percentage (\%) \\
\hline Warmer & 4 & 2 \\
Refrigerator & 2 & 1 \\
Room temperature & - & - \\
Others & - & - \\
No response & 194 & 97 \\
Total & 200 & 100 \\
\hline
\end{tabular}

Table 23 shows, that (2\%) of the mothers stored their left over formula in a "baby warmer" and (1\%) in the refrigerator, while (97\%) did not respond.

Table 24. Nutrition Knowledge of the Subjects.

\begin{tabular}{|c|c|c|c|c|c|c|c|}
\hline Questions & $\begin{array}{l}\text { Agree } \\
\text { Strongly } \\
\text { No } \% \\
\end{array}$ & $\begin{array}{l}\text { Agree } \\
\text { No } \%\end{array}$ & $\begin{array}{l}\text { Undecide } \\
\text { d } \\
\text { No } \% \\
\end{array}$ & $\begin{array}{l}\text { Disagree } \\
\text { No } \%\end{array}$ & $\begin{array}{l}\text { Strongly } \\
\text { Disagree } \\
\text { No } \% \\
\end{array}$ & $\begin{array}{l}\text { No } \\
\text { Response } \\
\text { No \% } \\
\end{array}$ & Total \\
\hline Mother's first breast secretion is excellent for the baby & 6030 & 136.5 & - & 2914.5 & $76 \quad 38$ & 2211 & 200 \\
\hline Children need a wide variety of foods to get adequate nutrition & 10050 & 4221 & 42 & 63 & - & $48 \quad 24$ & 200 \\
\hline Breast milk should be stopped before introduction of solid foods & 2211 & 105 & 21 & 4422 & 8643 & 3618 & 200 \\
\hline $\begin{array}{l}\text { A normal health person can get all the vitamins and minerals he } \\
\text { needs from food and does not need to take vitamin pills }\end{array}$ & 6030 & 3216 & 84 & 3417 & $30 \quad 15$ & 3618 & 200 \\
\hline $\begin{array}{l}\text { Pregnant women do not need more calories, proteins, vitamins } \\
\text { and minerals than they did before pregnancy }\end{array}$ & 4422 & 63 & 63 & $30 \quad 15$ & $30 \quad 15$ & 2010 & 200 \\
\hline $\begin{array}{l}\text { Cooking vegetables in large volume of water for a long time } \\
\text { removes source of the nutrients }\end{array}$ & 9648 & 5025 & 84 & 42 & 2412 & 189 & 200 \\
\hline Solid foods should be introduced at about four months of age & 3216 & 3015 & 2010 & 4020 & 4020 & 3819 & 200 \\
\hline Breast milk is best for the baby & 14271 & 168 & 63 & 21 & 21 & 3216 & 200 \\
\hline
\end{tabular}

From table 24 it could be observed that majority $38 \%$ (76) of the women strongly disagree that mothers first breast secretion is excellent for the baby, $30 \%$ (60) strongly agree, $43 \%$ (86) of the women strongly disagree that breast milk should be stopped before introduction of solid foods, $22 \%$ disagreed, whereas $11 \%$ (22) strongly agree. $5 \%$ agreed while $18 \%$ did not respond. In addition, $15 \%$ (30) strongly disagree that pregnant women do not need more calories, proteins, vitamins and minerals than they did before pregnancy $22 \%$ (44) agreed, $15 \%$ disagreed while $10 \%$ did not respond.

Table 25. Mean $\pm S D$ of the Parameters According to Feeding Method. And Sex

\begin{tabular}{lllll}
\hline parameters & EXBF Mean \pm SD & Non-EXBF Mean \pm SD & EXBF Mean \pm SD & Non-EXBF Mean \pm SD \\
\hline Age (weeks) & $9.860 \pm 3.32$ & $10.30 \pm 3.903$ & $9.735 \pm 3.610$ & $10.00 \pm 4.219$ \\
Birth wt (kg) & $3.655 \pm 0.57$ & $3.452 \pm 04943$ & $3.420 \pm 0.5447$ & $3.856 \pm 4664$ \\
PW (kg) & $6.415 \pm 1096$ & $6.3 \pm 1446$ & $5.968 \pm 1.111$ & $5.630 \pm 1.022$ \\
Length & $61.96 \pm 4.729$ & $61.4 \pm 5241$ & $60.92 \pm 4.812$ & $59.98 \pm 2.146$ \\
Head & $42.88 \pm 2.496$ & $41.86 \pm 2.474$ & $41.59 \pm 2.669$ & $40.92 \pm 2.146$ \\
Chest & $44.50 \pm 3.518$ & $44.04 \pm 2.680$ & $43.43 \pm 3.102$ & $42.78 \pm 0.4221$ \\
\hline
\end{tabular}

From the table above it could be observed that the mean age of the subjects were $(9.86 \pm 3.22)$ for males on exclusive breastfeeding, $(10.30 \pm 3.90)$ for males not exclusively

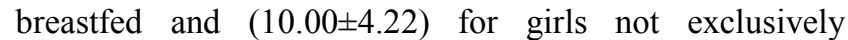
breastfed. The mean length of boys exclusively and not exclusively breastfed were $61.96 \pm 4.73$ and $61.40 \pm 5.24$ while girls exclusively breastfed were $60.92 \pm 4.81$ and $59.98 \pm 2.15$ respectively. This shows that their weights increased as they get older.

Table 26. Chi-Square Test: Test for Relationship.

\begin{tabular}{|c|c|c|c|c|}
\hline Variable & $\chi^{2}$ & P-Value & DF & Result \\
\hline Breastfed vs. non-breastfed & 57.22 & $<0.0001$ & 1 & $\mathrm{~S}$ \\
\hline Exclusive BF vs non-exclusive BF & 140.8 & $<0.0001$ & 1 & $\mathrm{~S}$ \\
\hline Education vs nutrition knowledge & 278.9 & $<0.0001$ & 5 & $\mathrm{~S}$ \\
\hline Occupation vs duration of EXBF & 62.61 & $<0.0001$ & 6 & $\mathrm{~S}$ \\
\hline Duration of breastfeeding daily vs satisfaction & 99.24 & $<0.0001$ & 5 & $\mathrm{~S}$ \\
\hline Ethnic group vs initiation of breastfeeding & 45.15 & $<0.0001$ & 4 & $\mathrm{~S}$ \\
\hline Education vs initiation of breastfeeding & 268.00 & $<0.0001$ & 4 & $\mathrm{~S}$ \\
\hline
\end{tabular}

Table 26, shows that there are associations or relationships between the variables. There were significant differences between mothers who breastfed exclusively and those who do not. There was also significant difference 
between occupation and duration of exclusive breastfeeding $(\mathrm{p}<0.0001)$.

Table 27. T-Test: Comparison of Two Means Boys: Exclusive breastfeeding vs. non-exclusive.

\begin{tabular}{lllll}
\hline Parameters & T-Value & DF & P-Value & $(\mathbf{P}<\mathbf{0 . 0 5})$ \\
\hline Birth Weight & 1.93 & 98 & 0.0565 & NS \\
Present Weight & 0.4332 & 98 & 0.6658 & NS \\
Length & 0.5609 & 98 & 0.0428 & NS \\
Head Circumference & 2.052 & 98 & 0.0428 & S \\
Chest Circumference & 0.7355 & 98 & 0.4638 & NS \\
\hline
\end{tabular}

Table 28. T- Test Girls: Exclusive Versus Non-Exclusive.

\begin{tabular}{lllll}
\hline Parameters & T-Value & DF & P-Value & $(\mathbf{P}<\mathbf{0 . 0 5})$ \\
\hline Birth Weight & 0.6094 & 98 & 0.5437 & NS \\
Present Weight & 2.675 & 98 & 0.0088 & S \\
Length & 1.443 & 98 & 0.1522 & NS \\
Head Circumference & 2.029 & 98 & 0.0451 & S \\
Chest Circumference & 2.221 & 98 & 0.0287 & NS \\
\hline
\end{tabular}

The table above showed that except for head circumference, there were no significant differences, with different $\mathrm{p}$ - values. This could be due to the fact that both were breastfed.

Table 29. T- Test: Boys Vs Girls (Exclusively Breastfed).

\begin{tabular}{lllll}
\hline Parameters & T-Value & DF & P-Value & $(\mathbf{P}<\mathbf{0 . 0 5})$ \\
\hline Birth Weight & 2.088 & 97 & 0.0394 & S \\
Present Weight & 1.924 & 97 & 0.0573 & NS \\
Length & 1.086 & 97 & 0.2801 & NS \\
Head Circumference & 2.481 & 97 & 0.0148 & S \\
Chest Circumference & 1.606 & 97 & 0.1115 & NS \\
\hline
\end{tabular}

Table 30. T- Test : Boys Vs Girls: Non Exclusive Breastfeeding.

\begin{tabular}{lllll}
\hline Parameters & T-Value & DF & P-Value & $(\mathbf{P}<\mathbf{0 . 0 5})$ \\
\hline Birth Weight & 0.6094 & 98 & 0.5437 & NS \\
Present Weight & 2.675 & 98 & 0.0088 & S \\
Length & 1.443 & 98 & 0.1522 & NS \\
Head Circumference & 2.029 & 98 & 0.0451 & S \\
Chest Circumference & 2.221 & 98 & 0.0287 & S \\
\hline
\end{tabular}

This follows the normal trend that boys have broader chest, bigger head and weight more at birth than girls.

Table 31. Weight of Boys: Exclusive Vs Non Exclusive.

\begin{tabular}{lllll}
\hline Exclusive & & \multicolumn{3}{l}{ Non-Exclusive } \\
\hline Std Dev. & Freq & $\%$ & Freq & $\%$ \\
-3 SD & - & - & - & - \\
-2 SD & 2 & 4 & 1 & 2 \\
-1 SD & 7 & 14 & 6 & 12 \\
Median & 18 & 36 & 18 & 36 \\
1 & 17 & 34 & 20 & 40 \\
2 & 6 & 12 & 3 & 6 \\
3 & 1 & 2 & 2 & 4 \\
Total & 51 & & & \\
\hline
\end{tabular}

Table 31 represents the weight of boys exclusively vs. non exclusively breastfed $36 \%$ (18) of the boys both exclusively and non exclusively breastfed fall within the normal range, $2 \%$ of exclusively breastfed are obese while $4 \%$ (2) of non exclusively breastfed are obese.
Table 32. Boys: Length Of Boys

\begin{tabular}{lllll}
\hline Exclusive & & \multicolumn{3}{l}{ Non-Exclusive } \\
\hline Std Dev. & Freq & $\%$ & Freq & $\%$ \\
-3SD & 1 & 2 & 1 & 2 \\
- 2SD & - & - & - & - \\
-1SD & 1 & 2 & 1 & 2 \\
Median & 18 & 36 & 22 & 44 \\
1 & 28 & 56 & 25 & 50 \\
2 & 2 & 4 & - & - \\
3 & - & - & 1 & 2 \\
\hline
\end{tabular}

Table 32 shows that the length of boys non-exclusively breastfed was higher than that of boys exclusively breastfed.

The table above summarizes the head circumference of boys exclusively and non - exclusively breastfed. Forty four percent $(44 \%)$ of the boys fall within the normal range while $46 \%$ (23) fall within the normal range among the non- exclusively breastfed infants.

Table 33. Boys: Head Circumference Z-Scores.

\begin{tabular}{lllll}
\hline Exclusive & & \multicolumn{3}{l}{ Non-Exclusive } \\
\hline Std Dev. & Freq & $\%$ & Freq & $\%$ \\
-3 SD & - & - & 1 & 2 \\
-2 SD & - & - & - & - \\
-1 SD & 5 & 10 & - & - \\
Median & 22 & 44 & 23 & 46 \\
+1 SD & 18 & 36 & 25 & 50 \\
+2 SD & 1 & 2 & 1 & 2 \\
$+3 S D$ & 4 & 8 & - & - \\
\hline
\end{tabular}

Table 34. Chest Circumference for Boys.

\begin{tabular}{lllll}
\hline Exclusive & & \multicolumn{3}{c}{ Non-Exclusive } \\
\hline Std Dev. & Freq & $\%$ & Freq & $\%$ \\
-3SD & 1 & 2 & - & - \\
- 2SD & - & - & 1 & 2 \\
-1SD & 2 & 4 & 8 & 16 \\
Median & 14 & 28 & 19 & 38 \\
1 & 32 & 64 & 15 & 30 \\
2 & 1 & 2 & 5 & 10 \\
3 & - & - & 2 & 4 \\
\hline
\end{tabular}

The chest circumference $28 \%$ (14) and 38\% (19) fell within the normal range for excusive and non- exclusive respectively.

Table 35. Z-Scores: Girls Exclusive Vs Non Exclusive (Weight).

\begin{tabular}{lllll}
\hline Exclusive & & \multicolumn{3}{c}{ Non-Exclusive } \\
\hline Std Dev. & Freq & $\%$ & Freq & $\%$ \\
-3SD & - & - & - & - \\
- 2SD & 1 & 2 & - & - \\
-1SD & 8 & 16.3 & - & - \\
Median & 16 & 32.7 & 43 & 86 \\
1 & 14 & 28.6 & 6 & 12 \\
2 & 8 & 16.3 & - & - \\
3 & 2 & 14.1 & 1 & 2 \\
\hline
\end{tabular}

The weight of boys not exclusively breastfed was higher than girls exclusively breastfed. 
Table 36. Girls Length.

\begin{tabular}{lllll}
\hline Exclusive & & \multicolumn{3}{l}{ Non-Exclusive } \\
\hline Std Dev. & Freq & $\%$ & Freq & $\%$ \\
-3SD & - & - & - & - \\
- 2SD & - & - & 2 & 4 \\
-1SD & 8 & 16.3 & 5 & 10 \\
Median & 15 & 30.6 & 13 & 26 \\
1 & 16 & 32.7 & 22 & 44 \\
2 & 8 & 16.3 & 8 & 16 \\
3 & 2 & 4.1 & - & - \\
\hline
\end{tabular}

Table 37. Girls Head Circumference.

\begin{tabular}{lllll}
\hline Exclusive & & \multicolumn{3}{c}{ Non-Exclusive } \\
\hline Std Dev. & Freq & $\%$ & Freq & $\%$ \\
-3SD & - & - & - & - \\
- 2SD & 1 & 2 & 2 & 4 \\
-1SD & 6 & 12.2 & 4 & 8 \\
Median & 16 & 32.7 & 15 & 30 \\
1SD & 20 & 40.8 & 23 & 46 \\
2SD & 4 & 8.2 & 6 & 12 \\
3SD & 2 & 4.1 & - & - \\
\hline
\end{tabular}

The length of girls exclusively breastfed was higher than girls not exclusively breasted, hence $30.6 \%$, (15) and $26 \%$ (13) respectively. None fell within the $-3 \mathrm{SD}$ for both groups whereas 4\% (2) of non exclusively breastfed fell under -2SD. None amongst the exclusively breastfed infants fell within the -2SD.

Table 38 shows the head circumference of the girls. Two percent $(2 \%)$ of the exclusively breastfed fell within -2SD while $4 \%$ of the non - exclusively breastfed fell within 2SD.

Table 38. Girls Chest Circumference.

\begin{tabular}{lllll}
\hline Exclusive & & \multicolumn{3}{l}{ Non-Exclusive } \\
\hline Std Dev. & Freq & $\%$ & Freq & $\%$ \\
-3SD & 1 & 2 & - & - \\
- 2SD & - & - & 1 & 2 \\
-1SD & 2 & 4 & 10 & 20 \\
Median & 14 & 28 & 14 & 28 \\
1SD & 32 & 64 & 16 & 32 \\
2SD & 1 & 2 & 8 & 16 \\
3SD & - & - & 1 & 2 \\
\hline
\end{tabular}

Table 38, summaries the chest circumference of girls exclusively breastfed and non-exclusively breastfed $28 \%$ (14) of both groups fell within the normal rang. 64\% (32) and $32 \%$ (16) fell within the -2 SD. Non fell within - 3 SD for the exclusively breastfed girls.

\section{Discussion, Conclusion and Recommendation}

The percentage of mothers who exclusively breastfed their infants to 24 weeks among the population attending the Mother of Christ Specialist Hospital Ogui Enugu was $85 \%$. This is much higher than $66 \%$ reported in Owerri Metropolis ${ }^{(14)}$. This reflects the positive impact of the baby friendly Hospital imitative (BFHI) programme coupled with the nutrition education given to mothers during their antenatal clinic days. The number of males exclusively breastfed were more by one. This portrays some form of preferential treatment given to males in terms of receiving the best in our environment than for girls.

Majority (40\%) of the mothers aged 26-30 years practiced exclusive breastfeeding. This could be due to their willingness to heed to advice of the health workers. A greater number of the mothers had formal education. This shows that the maternal empowerment made great contribution to their choice of breastfeeding. The self employed, unemployed and student mothers highly practiced exclusive breastfeeding while many of the working mothers stopped exclusive breastfeeding earlier. This was attributed to the short duration of maternity leave (31/2 months post partum).

The high knowledge of mothers (79\%) in this study was as a result of awareness creation with respect to exclusive breastfeeding as part of nutrition education given at antenatal, post natal and Infant Welfare Clinics and also promotional activities using the mass media. In terms of attitude, the high scores (79\%) and (65\%) actually did reflect in their practice of exclusive breastfeeding, despite the numerous and cultural barriers created by the lack of social support systems at the household and community levels.

The Z- scores (length of girls exclusively breastfed versus length of girls that exclusively breastfed showed accelerated growth rate amongst girls not exclusively breastfeed. The girls exclusively breastfed grew better than other group. The comparison between the two did not yield statistical significant difference in some of the parameters. However the observed trends were worth mentioning.

The t-test analysis for the difference between pairs of means of growth for boys exclusively breastfed and nonexclusively breastfed showed no statistical difference expect for head circumference for girls exclusively breastfed versus non exclusively breastfed. There were significant differences in their present weight, head and chest circumference. This shows that exclusively breastfed infants have advantage over non- exclusively breastfed infants.

The advantages of exclusive breastfeeding observed in this study reaffirm the need to continue to encourage and lay more emphasis on breastfeeding practices. The result of this finding adds support to the current WHO/UNICEF and ICHCS feeding recommendations which says that breastfeeding with good nutrition, is essential to achieving the UN millennium development goal.

\section{Conclusion}

The data from this study confirms that exclusive breastfeeding actually accelerated growth in weight, length, head circumference and chest circumference. However, non- exclusively breastfed exceeded in weight for boys.

Though there was no significant difference $(p>0.05)$. In some of the parameters, exclusive breastfeeding is best 
because of its advantages over non - exclusive breastfeeding. The mothers' knowledge of exclusive breastfeeding is quite appreciative. The result showed that a good number of them were really practicing exclusive breastfeeding. Exclusive breastfeeding practices have positive impact in the society. Female babies were exclusively breastfed as much as males to rule out the previous belief of preferential treatment. Age, educational level and occupation affected exclusive breast feeding which in turn affected the nutritional status of the babies positively.

\section{Recommendation}

Based on the findings of this study, the following recommendations have been proffered:

1. There should be adequate and effective maternity protection measures for all child- bearing working mothers in every sphere of life. These measures include adequate maternity leave up to $(6$ months post partum) nursing breaks and crèches at work places.

2. More efforts should be made to intensify the awareness on exclusive breastfeeding because there are still some misconceptions and wrong practices, which were found to be some of the factors affecting the nutritional status of infants. For instance, some mothers think that giving the baby water at least one or two times daily was part of exclusive breastfeeding while others think that giving formula occasionally is still part of it.

3. Dietitians/Nutritionists should intensity their nutrition education in antenatal clinics in both government and peripheral hospitals. This is because the choice of feeding practice depends a great' deal on the information received by the mother while still pregnant.

4. Every peripheral hospital should have at least one Nutritionist - Dietitian to ensure expert management.

5. Adoption and effective implementation of the National Policy on Infant and Young Child Feeding in Nigeria should be enforced at all levels of the government.

\section{References}

[1] Okwy-Nweke C. P., Anyanwu J. O., Maduforo A. N. (2014). Mothers Beliefs and Obstacles as Limitations in Promoting Exclusive Breastfeeding among Working Class Mothers Attending Infant Welfare Clinic at University of Nigeria Teaching Hospital (UNTH), Enugu State. Clinical Medicine Research. Vol. 3, No. 4, 2014, pp. 105-111. doi: $10.11648 /$ j.cmr.20140304.15
[2] Nwosu O. I. C., Nnam N. N., Ibeziako N. and Maduforo A.N. (2014) Development and Nutritional Evaluation of Infant Complementary Food from Maize (Zea Mays), Soybean (Glycine Max) and Moringa Oleifera Leaves. International Journal of Nutrition and Food Sciences. Vol. 3, No. 4, 2014, pp. 290-299. doi: 10.11648/j.ijnfs.20140304.19

[3] Martorell R, Kettel K. L, and Schroeder D.G. (1994) Reversibility of stunting: epidemiological findings in children from developing countries. Eur J Clin Nutr; S45S57.

[4] WHO (2001) The optimal duration of exclusive breastfeeding: report of an expert consultation (WHO/FCH/CAH/01.24) Geneva: March 2001.

[5] Nigeria Demographic and Health Survey (2013). National Population Commission Federal Republic of Nigeria Abuja, Nigeria. MEASURE DHS, ICF Macro Calverton, Maryland, USA,

[6] United Nations Children's Fund (UNICEF) (2012) Infant and Young Child Feeding. United Nations Children's Fund (UNICEF) June 2012

[7] Hallgren, O. Aits, S. Brest, P. (2008). Infant Nutrition, breastfeeding and obesity. British Medical journal

[8] Maduforo, A.N. And Onuoha R.O. (2011) Relativities of Exclusive Breastfeeding between Urban and Rural Lactating Women in Imo State. Journal of Research In National Development (Jorind) Volume 9 Number 1(a) $31-$ 36. ISSN $1596-8308$ JUNE, 2011. www.transcampus.org/journal; www.ajol.info/journals/jorind

[9] Aso, C. U (1999); Baby friendly Hospital initiative, A paper presentation, a global and National perspective. American Journal on Public Health.

[10] United Nations Children's Fund (UNICEF) (2014). The state of the world's children 2014 in numbers: Revealing disparities, advancing children's rights: Every child counts. UNICEF

[11] Nigeria Demographic and Health Survey (NDHS) (2003). National Population Commission Federal Republic of Nigeria Abuja, Nigeria. MEASURE DHS, ICF Macro Calverton, Maryland, USA.

[12] Nigeria Demographic and Health Survey (NDHS) (2013). National Population Commission Federal Republic of Nigeria Abuja, Nigeria. MEASURE DHS, ICF Macro Calverton, Maryland, USA.

[13] Government of Federal Republic of Nigeria (2010). $M D G$ Report 2010: Nigeria Millennium Development Goals. Abuja, Nigeria: Government of Federal Republic of Nigeria.

[14] Maduforo, A.N, Ubah N.C and Obiakor - Okeke P.N. (2013) The Practice Of Exclusive Breastfeeding By Lactating Women In Owerri Metropolis, Imo State, Nigeria. Glo. Adv. Res. J. Med. Med. Sci. January 2013 2(1): 013-019 http://www.garj.org/garjmms. 